\title{
Validated Stability-indicating HPTLC Determination of Baclofen in Bulk Drug, Pharmaceutical Formulations and Real Human Urine and Plasma.
}

\author{
Safaa F. Saleh ${ }^{1,2^{*}}$, Mahmoud A. Omar ${ }^{1}$ and Sayed M. Derayea ${ }^{1}$ \\ 1: Analytical Chemistry Department, Faculty of Pharmacy, Minia University, Minia, Egypt \\ 2: Pharmaceutical chemistry department, Faculty of pharmacy, Jizan University, Kingdom of Saudia Arabia.
}

E-mail address1: safaaafathy@ymail.com

E-mail address2: momar1971g@yahoo.com

E-mail address3: sayed_derayea@yahoo.com

\begin{abstract}
A simple, highly selective and stability-indicating high-performance thin-layer chromatographic method was developed and validated for the analysis of baclofen in bulk powder, pharmaceutical formulations and human urine and in and real human plasma. The method employed TLC aluminum plates precoated with silica gel $60 \mathrm{~F}_{254}$ as the stationary phase. The solvent system consisted of butanol-acetic acid-water (3.0: 0.5: 0.5, v/v/v). This system was found to give compact spots for baclofen ( $R_{\mathrm{f}}$ value of 0.54$)$. Densitometric analysis was carried out in the absorbance mode at $238 \mathrm{~nm}$. The linear regression analysis data for the calibration plot showed good linear relationship $\left(r^{2}=0.9983\right)$ in the concentration range 1.5-7.5 $\mu \mathrm{g}$ per spot. The analytical performance of the method was fully validated, and the results were satisfactory. The limits of detection and quantitation were 0.31 and $1.03 \mu \mathrm{g}$ per spot, respectively. Baclofen was subjected to acid and alkali hydrolysis, oxidation and photodegradation. The degraded product was well separated from the pure drug. Results indicate that the drug is stable against light and basic conditions. However, additional peaks were observed at $R_{\mathrm{f}}$ value of 0.65 and at $R_{f}$ value of 0.14 with hydrogen peroxide and hydrochloric acid respectively, indicating that the drug is susceptible to oxidation and acid degradation. The method was applied for the analysis of baclofen in commercial tablets and the results were similar to those obtained using the reference method. As the method could effectively separate the drug from its degradation product, it can be employed as a stability-indicating one. The high sensitivity of the proposed method allowed determination of baclofen in real human urine and plasma.
\end{abstract}

\section{Keywords}

- Baclofen; HPTLC; Stability indicating; Degradation; Human Plasma; Urine.

${ }^{*}$ Corresponding Author Tel: + (966)507101572- (+2)01000578278

E-mail address:safaafathy@ymail.com

\section{Council for Innovative Research}

Journal: Journal of Advances in Chemistry

Vol. 8, No. 1

editor@cirworld.com

www.cirworld.com, member.cirworld.com

1545 | P a g e

March 12,2014 


\section{INTRODUCTION}

Baclofen (4-amino-3-p-chlorophenyl butyric acid, BAL, "Figure 1", the first clinical application of selective $\mathrm{Y}^{-}$ aminobutyric acid has been widely used for the symptomatic relief of muscular spasm and multiple sclerosis caused by spinal or cerebral injury since its introduction in 1967 [1]. Unlike natural amino acids, $\boldsymbol{B A L}$ is capable of passing a bloodbrain barrier. It is rapidly adsorbed in the human body after oral administration and almost completely recovered unchanged in urine [2]. Its metabolism and mechanism of pharmacological action in humans is still poorly recognized. Consequently, development of a highly sensitive and specific method for the trace analysis of $\boldsymbol{B A L}$ is urgently required.

Several analytical methods have been reported for the determination of $\boldsymbol{B A L}$. These methods include; spectrophotometry $[3,4]$, potentiometry [5], thin-layer chromatography [6], gas chromatography [7], capillary electrophoresis [8, 9] and highperformance liquid chromatography (HPLC) coupled with different kinds of detectors [10 - 17]. For HPLC with conventional detection systems, such as UV-vis or fluorescence detectors, BAL needs to be derivatized because solution of BAL does not show obvious absorption or fluorescence. For this reason, chemical several derivatizing reagents [11-17] were applied to transform the analytes into derivatives that can be sensitively detected.

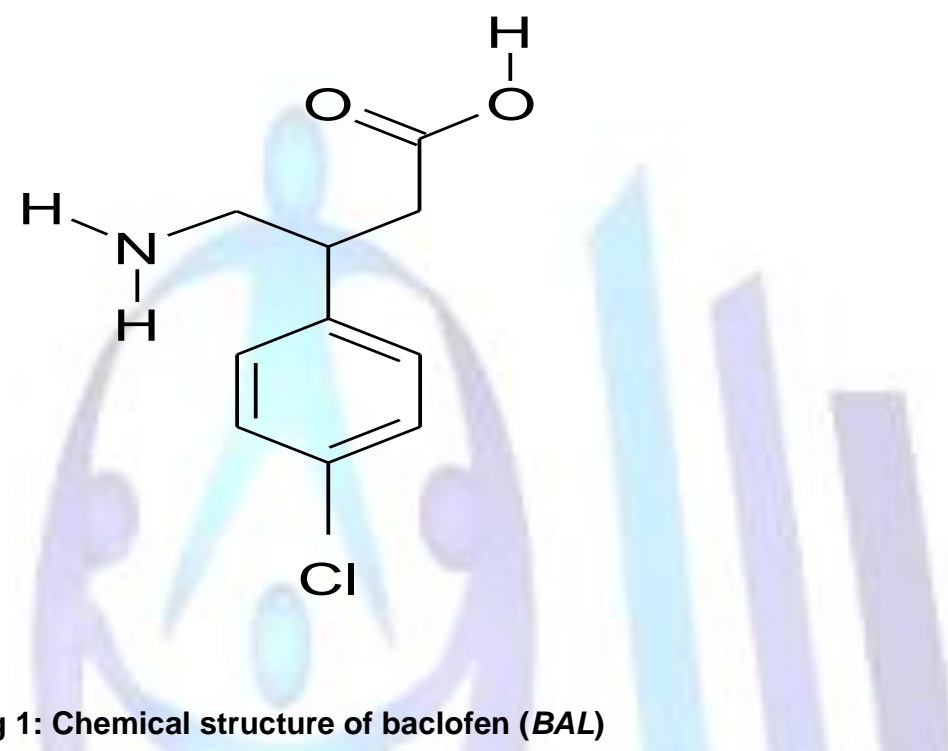

The International Conference on Harmonization $(\mathrm{ICH})$ guideline entitled 'stability testing of the drug substances and products' requires the stress testing to be carried out to elucidate the inherent stability characteristics of the active substance [18]. An ideal stability-indicating method is one that quantifies the drug per se and also resolves its degradation products. Nowadays, HPTLC is becoming a routine analytical technique in analytical laboratories due to its advantages [19]. The major advantage of HPTLC is that several samples can be run simultaneously using a small quantity of mobile phase [19]. This reduces analysis time, cost per analysis and possibilities of pollution of the environment. The aim of the present work is to develop a simple, and promising stability-indicating densitometric method that can be applied at qualitycontrol laboratories for the estimation of baclofen in pure form, in pharmaceutical tablets and in artificially degraded sample.

\section{EXPERIMENTAL}

\subsection{Materials}

Baclofen was obtained as a gift from Novartis Pharma, (Cairo, Egypt). All chemicals and reagents used were of analytical grade. Acetic acid, hydrochloric acid, hydrogen peroxide (30 volume), sodium hydroxide and Butanol were purchased from El-Nasr Chemical Co. (Cairo, Egypt). baclofen tablets (Novartis Pharma, Cairo, EGYPT), (Pharopharma A.R.E., Cairo, EGYPT) and (Misr, Cairo, EGYPT) labeled to contain $10 \mathrm{mg}$ baclofen were purchased from local mark.

\subsection{HPTLC instrumentation}

Chromatographic separation was performed on aluminum plate precoated with silica gel $60 \mathrm{~F}_{254},(20 \mathrm{~cm} \times 10 \mathrm{~cm}$ with 250 $\mu \mathrm{m}$ thickness) (Merck, Darmstadt, Germany). The samples were spotted with a Camag micro-syringe $100 \mu$, using a Camag Linomat 5 autosampler, (Camag, Muttenz, Switzerland). Densitometric scanning was performed on Camag TLC scanner 3 S / N 130319 in the absorbance mode utilizing deuterium lamp as a source of radiation with WINCATS software (Camag, Muttenz, Switzerland).

\subsection{Chromatographic conditions}

Aliquot amount of the working standard or sample solutions were spotted on the plate in the form of bands of width 3 $\mathrm{mm}$ with $100 \mu \mathrm{l}$ micro-syringe, using autosampler. A constant application rate of $0.1 \mu \mathrm{l} / \mathrm{s}$ was employed and space between two bands was $3 \mathrm{~cm}$. The bands were applied at $1 \mathrm{~cm}$ from the bottom edge of the plate. The plate was then allowed to dry on air for $5 \mathrm{~min}$ before its transfer to the TLC tank for the development. The mobile phase consisted of 
butanol-acetic acid-water (3.0: 0.5: 0.5, v/v/v).. Linear ascending development was carried out in chromatographic chamber previously saturated with the mobile phase for $15 \mathrm{~min}$ at room temperature. The length of chromatogram run was $8 \mathrm{~cm}$ subsequent to the development. TLC plates were dried in a current of air with the help of an air-dryer. Densitometric scanning was performed at $20 \mathrm{~mm} / \mathrm{s}$ scanning speed and the slit dimension was kept at $6.0 \times 0.30 \mu \mathrm{m}$. The TLC chromatogram was manipulated by WINCATS software.

\subsection{Standard solution preparation}

Stock solutions containing baclofen were prepared by dissolving $30 \mathrm{mg}$ of baclofen in $1 \mathrm{ml} 0.05 \mathrm{M} \mathrm{H}_{2} \mathrm{SO}_{4}$ and $\mathrm{completed}$ to $10 \mathrm{ml}$ with methanol.

\subsection{Calibration curves of baclofen}

Different volumes of stock solution, $0.5,0.9,1.3,1.7,2.1$ and $2.5 \mu \mathrm{l}$, were spotted in triplicate on TLC plate to obtain concentrations of $1.5,2.7,3.9,5.1,6.3$ and $7.5 \mu \mathrm{g}$ per spot of baclofen, respectively, then the densitometric analysis was performed as described under the Section 2.3. The calibration curve was established by plotting the average peak area versus the corresponding concentration of the spot and the data was analyzed by least-square linear regression analysis and the linear regression equation was estimated.

\subsection{Method validation}

\subsubsection{Precision}

Precision was checked at three concentration levels (1.5, 3.9 and $6.3 \mu \mathrm{g}$ per spot), four replicate measurements were recorded at each concentration level.

\subsubsection{Robustness of the method}

The robustness of the proposed method was examined by introducing small changes in the mobile phase composition and examining wavelength. Mobile phases having different composition of butanol-acetic acid-water (2.9: 0.6 : 0.5 and 3.1: $0.4: 0.5, \mathrm{v} / \mathrm{v} / \mathrm{v}$. and different wave length $(233 \mathrm{~nm}$ and $243 \mathrm{~nm})$ were tried at three different concentration levels of (1.5, 3.9 and $6.3 \mu \mathrm{g}$ per spot).

\subsubsection{Recovery studies}

Aliquot amounts of the dosage forms extract were spiked with extra 50,100 and $150 \%$ of the standard baclofen and the mixtures were reanalyzed in triplicate by the proposed method. This was done to check for the recovery of the drug at different levels in the formulations.

\subsection{Analysis of the commercial formulation}

The content of baclofen in three commercial formulation (Baclofen: $10 \mathrm{mg}$ per tablet, Lioresal: $10 \mathrm{mg}$ per tablet and Mylobac: $10 \mathrm{mg}$ per tablet), Ten tablets of baclofen were accurately weighed and finely powdered. An amount of the powdered tablets was accurately weighed equivalent to $150 \mathrm{mg}$ of baclofen and extracted with $5 \mathrm{ml} 0.05 \mathrm{M} \mathrm{H}_{2} \mathrm{SO}_{4}$ and 20 $\mathrm{ml}$ with methanol by sonication for $30 \mathrm{~min}$. Then completed to $50 \mathrm{ml}$ with methanol. The resulting solution was centrifuged at $3000 \mathrm{rpm}$ for $5 \mathrm{~min}$ and supernatant was analyzed for drug content. Four replicates at three concentration levels (1.5, 3.9 and $6.3 \mu \mathrm{g}$ per spot of baclofen) were applied on TLC plate followed by development and scanning as described in Section 2.3.

\subsection{Forced degradation of baclofen}

Acid and base induced degradation were carried out by adding $5 \mathrm{ml}$ of $5 \mathrm{~N}$ aqueous $\mathrm{HCl}$ or $5 \mathrm{~N}$ aqueous $\mathrm{NaOH}$ to 20 $\mathrm{ml}$ of baclofen working solution $(3 \mathrm{mg} / \mathrm{ml})$. The mixtures were heated at reflux for $6 \mathrm{hrs}$. Oxidative degradation with hydrogen peroxide $(30.0 \% \mathrm{v} / \mathrm{v})$ was carried out at the same manner but without reflux. These degradation procedures were performed in the dark in order to exclude the possible degradative effect of light. Photochemical stability was studied by exposing the working solution to direct daylight for $24 \mathrm{~h}$. The resultant solution was applied on TLC plate $(1.5 \mu \mathrm{g} / \mathrm{spot})$ and the chromatograms were run as described in Section 2.3.

\subsection{Real human plasma of baclofen}

Procedure for Real Human Plasma baclofen (Lioresal $25 \mathrm{mg}$ tablet) was taken orally by 12 hours fasting healthy human volunteers, then a $5.0-\mathrm{ml}$ sample of human blood was taken by using calibrated heparinized syringe after $3 \mathrm{~h}$ from baclofen taken [24], centrifuged at 4,000 rpm for $30 \mathrm{~min}$. Then, into a 10-ml stoppered calibrated tube, $1.0 \mathrm{ml}$ of obtained plasma was treated with $2.0 \mathrm{ml}$ of acetonitrile, and the resultant solution was diluted to $10.0 \mathrm{ml}$ with distilled water. The sample was centrifuged at $4,000 \mathrm{rpm}$ for $20 \mathrm{~min}$. A certain volume of this supernatant was diluted with methanol to obtain concentration within the concentration range for studied drug. Then, the chromatograms were run as described in Section 2.3. This process was repeated three times to accomplish intraday and interday assay. 


\subsection{Real human urine of baclofen}

Procedure for Real Human Urine baclofen (Lioresal $25 \mathrm{mg}$ tablet) was taken orally by 12 hours fasting healthy human volunteers, and the urine samples were collected $12 \mathrm{~h}$ after the administration and stored in flasks at $-20^{\circ} \mathrm{C}$ prior to analysis [24]. Acertain volume of this sample was diluted with methanol to obtain concentration within the concentration range for studied drug. Then, the chromatograms were run as described in Section 2.3. This process was repeated three times to accomplish intraday and interday assay.

\section{RESULTS AND DISCUSSION}

\subsection{Method development}

TLC procedure was optimized with a view to develop a stability-indicating assay method. Both the pure drug and the degraded one were spotted on TLC plates and run in different solvent systems. Initially, butanol-acetic acid in varying ratios was tried. The mobile phase butanol-acetic acid $(3.0: 0.5, \mathrm{v} / \mathrm{v})$ gave good resolution with $\mathrm{R}_{\mathrm{F}}$ value of 0.56 for baclofen and $0.65,0.14$ for degradation with hydrogen peroxide and hydrochloric acid respectively but the peaks have tailing. Addition of $0.5 \mathrm{ml}$ water to the above mobile phase gave compact spots for both drug and the degradant. Finally, the mobile phase consisting of butanol-acetic acid-water (3.0: 0.5: 0.5, v/v/v) gave a sharp and symmetrical peak. Welldefined spots were obtained when the chamber was saturated with the mobile phase for 15 min at room temperature.

\subsection{Method validation}

Validation was done following the ICH guidelines [21].The method was validated in terms of linearity, accuracy, inter-day and intra-day precision, robustness, and repeatability of sample application.

Linearity: "Figure 2" illustrate the linear calibration curve which constructed for baclofen by measuring the peak areas of triplicate bands at ten increasing concentrations $1.5,2.7,3.9,5.1,6.3,7.5 \mu \mathrm{g}$ per spot of baclofen .The curves were constructed by plotting the average peak areas against the corresponding concentration of the spot. Linear regression analysis was applied to calculate the analytical parameters of the constructed curve. The linear regression analysis data for the calibration plots showed good linear relationship with regression coefficients $\left(r^{2}\right)$ of 0.9983 over the concentration range 1.5-7.5 $\mu \mathrm{g}$ per spot.

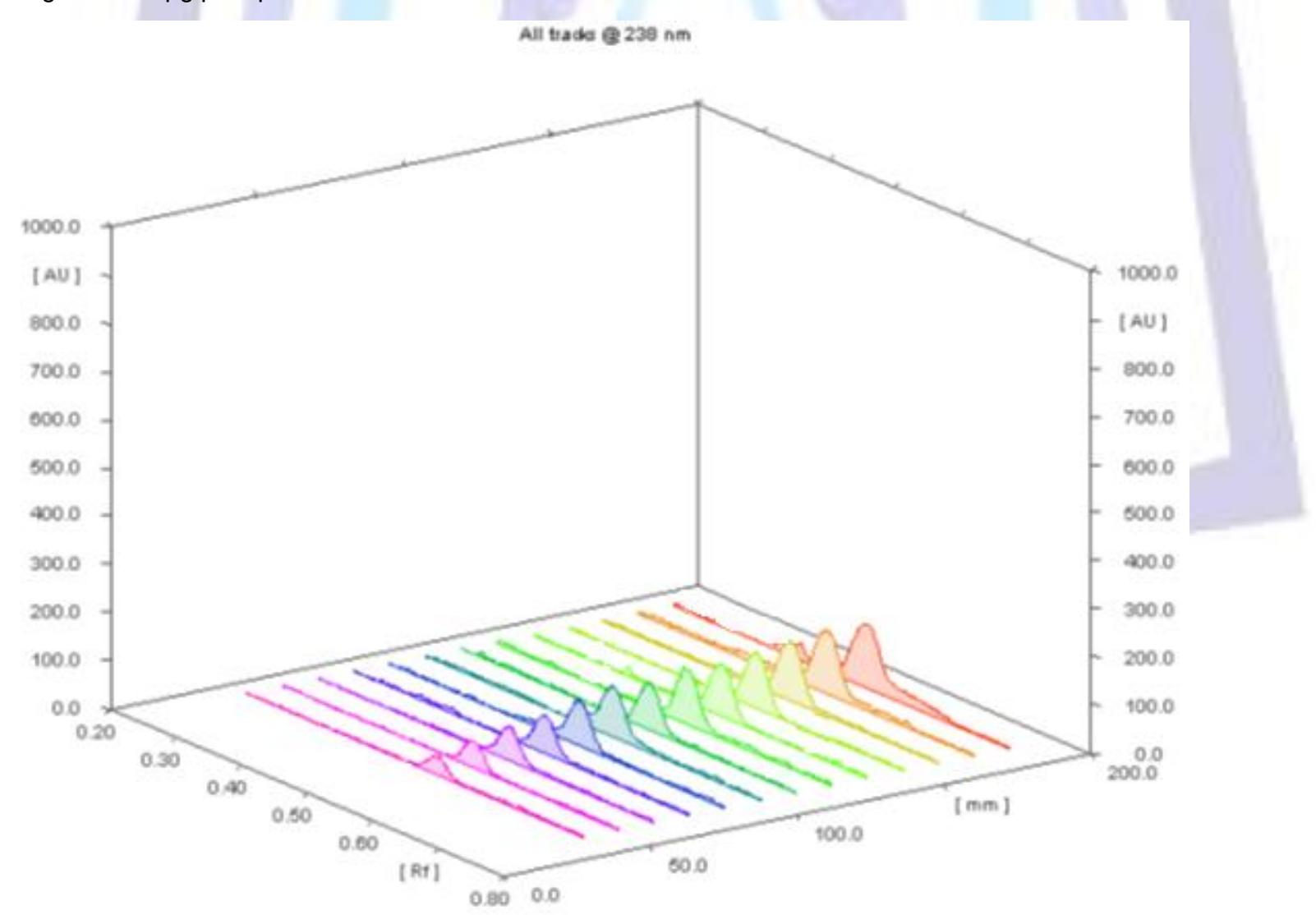

Fig 2: Chromatograms of pure baclofen $\left(R_{\mathrm{f}}\right.$ : 0.54$)$ using silica gel $60 \mathrm{~F}_{254}$ as the stationary phase, mixture of butanol-acetic acid-water (3.0: 0.5: $0.5, \mathrm{v} / \mathrm{v} / \mathrm{v})$ as mobile phase and absorbance mode at $238 \mathrm{~nm}$. 
Limit of detection (LOD) and limit of quantitation (LOQ): were calculated based on standard deviation of response and the slope of calibration curve. The limit of detection was expressed

as: $L O D=3 \sigma / S$ whlie $L O Q=10 \sigma / S$

Where $\boldsymbol{\sigma}$ is the standard deviation of intercept. $\mathbf{S}$ is the slope of calibration curve.

"Table 1", Summarize the result of the calculated detection limits and quantitation were 0.31 and $1.03 \mu \mathrm{g}$ per spot, respectively, indicating the high sensitivity of the proposed method.

Table 1. Analytical parameters for the proposed TLC method for determination of baclofen.

\begin{tabular}{|c|c|}
\hline Parameters & Results \\
\hline Linearity Range ( $\mu \mathrm{g} / \mathrm{spot})$ & $1.5-7.5$ \\
\hline Correlation coefficient (r) & 0.9991 \\
\hline Determination coefficient $\left(r^{2}\right)$ & 0.9983 \\
\hline Intercept (a) \pm SD & $261.8 \pm 71.8$ \\
\hline Confidence limit of intercept ${ }^{b}$ & 157.56 \\
\hline Slope (b) \pm SD & $333.07 \pm 13.6$ \\
\hline Confidence limit of slope ${ }^{\mathrm{b}}$ & 312.04 \\
\hline LOD ( $\mu \mathrm{g} / \mathrm{spot})$ & 0.31 \\
\hline LOQ ( $\mu \mathrm{g} / \mathrm{spot})$ & 1.03 \\
\hline
\end{tabular}

Precision: The repeatability of sample application was expressed in terms of \% RSD. The intra- and inter-day precisions were carried out at three different concentration levels, i.e. 1.5, 3.0, $6.3 \mu \mathrm{g} / \mathrm{spot}$. "Table 2", Summarize the result of Inter- and intra-day precision study and the repeatability of sample application. The calculated relative standard deviation values were below $2 \%$ indicating good repeatability and reliability of the proposed method [21] and [22].

Table 2. The repeatability of sample application and Intra- and inter-day precision for the determination of baclofen by the proposed HPTLC method.

\begin{tabular}{|c|c|c|c|c|}
\hline \multirow{2}{*}{$\begin{array}{c}\text { Amount } \\
\left(\mu \text { p per spot }^{*}\right.\end{array}$} & \multicolumn{2}{|c|}{ Intra-day precision } & \multicolumn{2}{c|}{ Inter-day precision } \\
\cline { 2 - 5 } & $\%$ Recovery $^{\mathrm{a}} \pm \%$ RSD & SE & \% Recovery ${ }^{\mathrm{a}} \pm$ \% RSD & SE \\
\hline 1.5 & $99.6 \pm 1.33$ & 0.66 & $98.2 \pm 0.27$ & 0.16 \\
\hline 3.0 & $99.7 \pm 1.24$ & 0.62 & $98.5 \pm 0.30$ & 0.17 \\
\hline 6.3 & $99.9 \pm 1.19$ & 0.60 & $99.5 \pm 1.11$ & 0.64 \\
\hline
\end{tabular}

a the value is the average of four determinations.

Robustness: "Table 3", Summarize the result of the robustness of the method which carried out by introducing small changes in the mobile phase composition, wave length, and examining the effects on the results. By spotting three different concentration levels of $1.5,3.0,6.3 \mu \mathrm{g} / \mathrm{spot}$.It was found that there is no change in the results. 
Table 3. Robustness for determination of baclofen by the proposed HPTLC method.

\begin{tabular}{lccc}
\hline \multirow{2}{*}{ Variation } & \multicolumn{3}{c}{$\%$ Recovery $^{\mathrm{a}} \pm \%$ RSD } \\
\cline { 2 - 4 } & $\mathbf{1 . 5}(\boldsymbol{\mu g}$ per spot) & $\mathbf{3 . 0}(\boldsymbol{\mu g}$ per spot) & $\mathbf{6 . 3}$ ( $\boldsymbol{\mu g}$ per spot) \\
\hline $\begin{array}{l}\text { Optimum } \\
\text { condition }\end{array}$ & $99.1 \pm 0.8$ & $99.9 \pm 1.2$ & $99.9 \pm 0.4$
\end{tabular}

1-Mobile phase composition

$(2.9: 0.6: 0.5)$

$(3.1: 0.4: 0.5)$
$99.1 \pm 0.7$

$99.5 \pm 0.9$

2- Wave length changes butanol-acetic acid-water $(3.0: 0.5: 0.5, \mathrm{v} / \mathrm{v} / \mathrm{v})$

$99.1 \pm 1.1$

$98.8 \pm 1.2$

$100.2 \pm 0.8$

$99.2 \pm 0.6$

$238 \mathrm{~nm}$

$100.1 \pm 0.9$

$233 \mathrm{~nm}$

$98.4 \pm 0.8$

$99.7 \pm 1.2$

$99.0 \pm 1.3$

$243 \mathrm{~nm}$

$99.0 \pm 1.5$

$100.0 \pm 0.5$

${ }^{a}$ the value is the average of four determinations.

Accuracy: Recovery studies of the drugs were carried out for estimation of the accuracy parameters of the proposed method. These studies were carried out at three levels i.e. using standard addition method. The obtained value for the commercial formulation was found to be within the limits which summarized in "Table 4", The low RSD value (<2) indicated the suitability of the method for routine analysis of baclofen in pharmaceutical tablets.

Table 4. Standard addition method for the recovery studies

\begin{tabular}{cccc}
\hline$\%$ Drug added & Total content $(\mu \mathrm{g} / \mathbf{s p o t})$ & \% Recovery ${ }^{\mathbf{a}} \pm$ SD & SE \\
\hline 0 & 1.5 & $99.2 \pm 0.61$ & 0.35 \\
50 & 2.25 & $99.6 \pm 1.72$ & 0.99 \\
100 & 3 & $98.0 \pm 0.89$ & 0.50 \\
150 & 3.75 & $99.4 \pm 1.43$ & 0.82 \\
\hline
\end{tabular}

a: the value is the average of three determinations.

\subsection{Stability-indicating study}

The stability of baclofen solution was examined at different stress conditions. $5 \mathrm{~N}$ aqueous HCL "Figure 3b" results in the appearance of an additional peak at $R_{f}$ value of 0.14 , The new peak appears before the parent drug peak. This gives an indication that the degradation product is more hydrophilic than the parent drug, while oxidation with hydrogen peroxide "Figure 3d" result in the appearance of an additional peak at $R_{f}$ value of 0.65 , the new peak appears after the parent drug peak. This gives an indication that the degradation product is more lipophilic than the parent drug. The exposure to alkaline hydrolysis and daylight ("Figure 3a, 3e", respectively) did not produce any significant effect on the drug chromatograms and only one peak was observed at $R_{f}=0.54$ which corresponds to baclofen itself. This is an evidence of the stability of baclofen against alkaline hydrolysis and photodegradation and liability of baclofen for acidic hydrolysis and oxidative degradation. 


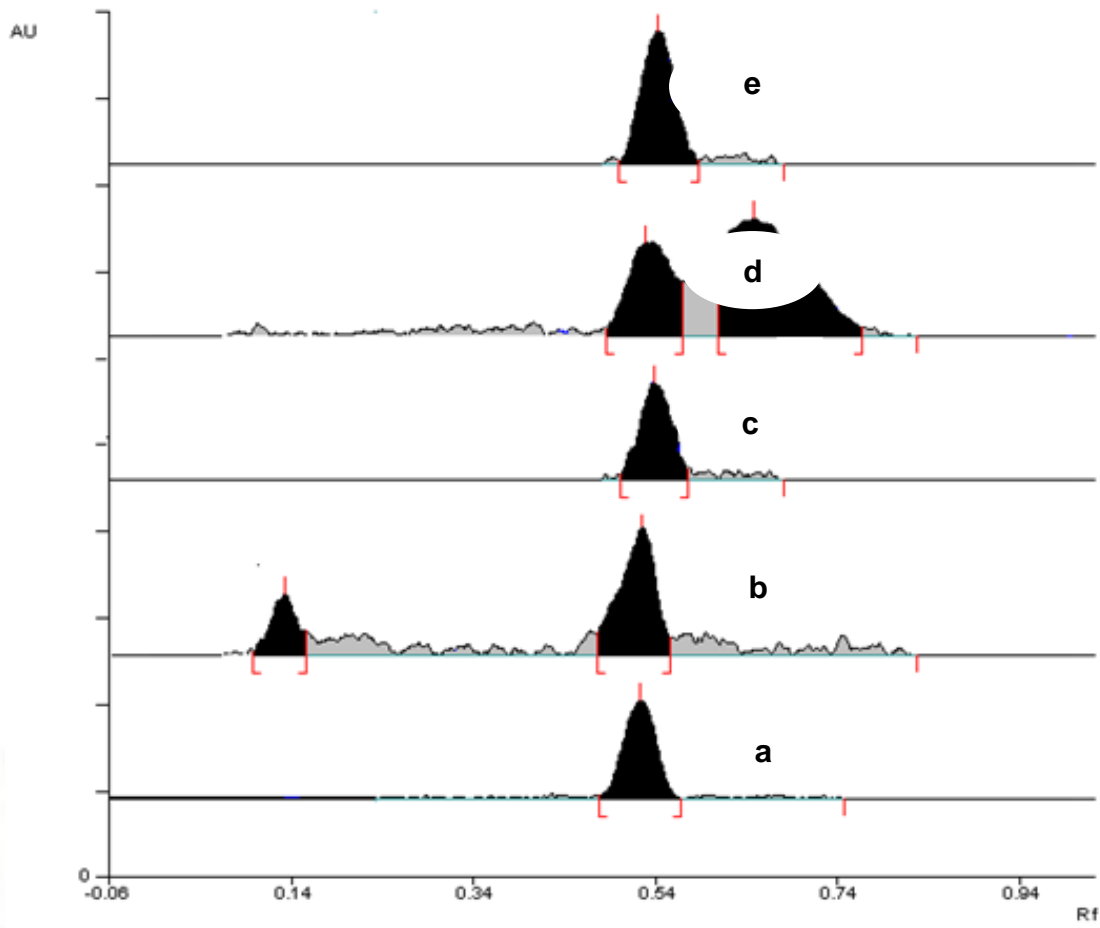

Fig 3: Chromatograms of baclofen and its degraded products: (a) pure drug: peak 1 ( $R_{\mathrm{f}}$ : 0.54$)$ is of baclofen; (b) degraded with acid: peak $1\left(R_{\mathrm{f}}: 0.14\right)$ is of degraded product, peak $2\left(R_{\mathrm{f}}: 0.54\right)$ is of baclofen; (c) base-treated: peak $1\left(R_{f}: 0.54\right)$ is of baclofen; (d) degraded with hydrogen peroxide: peak $1\left(R_{f}: 0.54\right)$ is of baclofen, peak $2\left(R_{f}: 0.65\right)$ is of degraded product; (e) photo-treated: peak $1\left(R_{\mathrm{f}}: 0.54\right)$ is of baclofen.

\subsection{Application to commercial tablets}

The chromatogram of the drug samples extracted from commercial formulation showed only one spot at $R_{f} 0.54$. It may therefore be inferred that the degradation of baclofen had not occurred in the analyzed commercial formulation. The presence of excipients in the tablets did not produce any significant interference with the analysis. The result of the present method was statistically compared with that of the reference method [23]. "Table 5", shows that the calculated tand $F$ - values at $95 \%$ confidence level are less than the tabulated t- value (2.13) and F value (4.10). This confirms that there is no significant difference between the performance of the developed method and the reference method in regarded to accuracy and precision.

Table 5. Analysis of commercial tablets containing baclofen using the proposed and reported methods.

\begin{tabular}{|c|c|c|c|c|c|}
\hline \multirow{2}{*}{$\begin{array}{c}\text { Dosage } \\
\text { forms }\end{array}$} & \multirow{2}{*}{$\begin{array}{c}\text { Labeled } \\
\text { content }\end{array}$} & \multicolumn{2}{|c|}{ \% Recovery $\mathbf{S S D}^{\mathbf{a}}$} & \multirow{2}{*}{ t- value $^{\mathbf{b}}$} & \multirow{2}{*}{ F- value $^{\mathbf{b}}$} \\
\cline { 3 - 6 } & & Reported method & Proposed method & & \\
\hline Baclofen & $10 \mathrm{mg}$ & $100.2 \pm 0.87$ & $98.9 \pm 0.80$ & 1.62 & 1.21 \\
\hline Lioresal & $10 \mathrm{mg}$ & $99.7 \pm 0.29$ & $99.0 \pm 0.40$ & 1.05 & 1.96 \\
\hline Mylobac & $10 \mathrm{mg}$ & $99.9 \pm 0.49$ & $99.1 \pm 0.32$ & 1.28 & 2.36 \\
\hline
\end{tabular}

\footnotetext{
${ }^{a}$ Average of three determinations. ${ }^{b}$ Tabulated values for $t$ and $F$. are 2.13 and 4.10 respectively.
} 


\subsection{Analysis of cited drug in Real Human Plasma}

Baclofen is rapidly and completely absorbed from the gastro-intestinal tract. baclofen is absorbed rapidly after oral administration of $25 \mathrm{mg}$ producing a mean peak plasma concentration of $20 \mathrm{mg} / \mathrm{L}$ in $3 \mathrm{~h}$ [24]. So, percent recovery of baclofen in plasma was calculated by using the following equation [25].

$\%$ Recovery $_{\text {in vivo }}=\left(\right.$ concentration found $_{\text {f concentration }}$ taken $) \times 100$

\section{Where,}

$\%$ Recovery in vivo is \% recovery for drug in real human sample.

Concentration found is concentration of the drug founded in real human sample.

Concentration taken is concentration of the drug reported in real human sample.

Percent recoveries after application of the proposed method in real human plasma sample by intra- and interday assay were shown in "Table 6", "Figure 4" illustrate the chromatogram of analysis of baclofen in real human plasma.

Table 6. \% Recoveries after application of the proposed method for determination of baclofen in real human plasma sample.

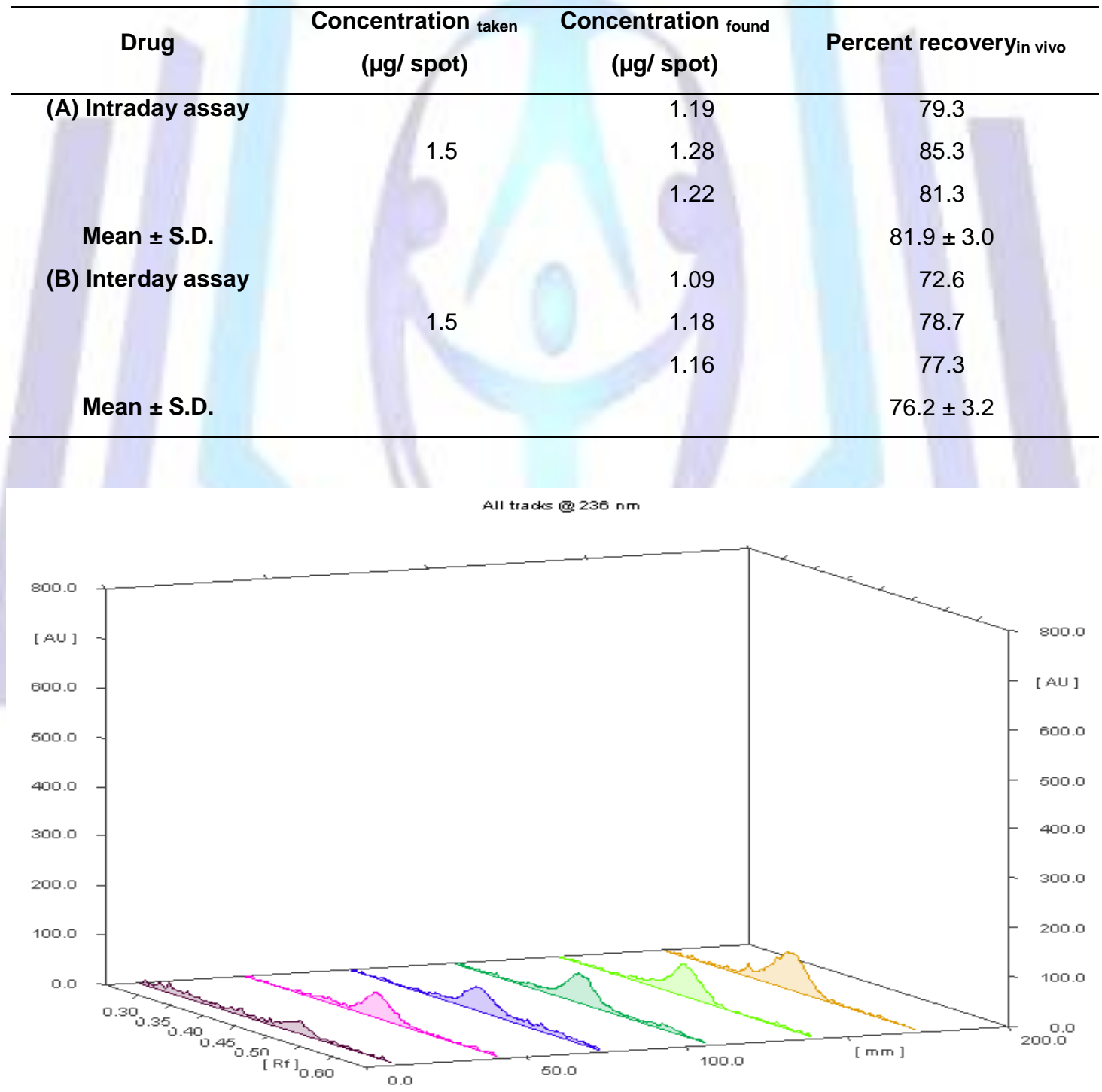

Fig 4: Chromatograms of baclofen in Real Human Plasma. 


\subsection{Analysis of cited drugs in Real Human Urine}

Approximately $70 \%$ of baclofen is eliminated in urine in unchanged form. Baclofen is absorbed rapidly after oral administration of $25 \mathrm{mg}$ producing a mean peak elimination concentration of $17.5 \mathrm{mg} / \mathrm{L}$ in $3 \mathrm{~h}$ [24]. So, percent recovery of baclofen in urine was calculated by using the following equation.

$\%$ Recovery in vivo $=($ concentration found $/$ concentration taken $) \times 100$

Where,

$\%$ Recovery in vivo is \% recovery for drug in real human sample.

Concentration found is concentration of the drug founded in real human sample.

Concentration taken is concentration of the drug reported in real human sample.

Percent recoveries after application of the proposed method in real human urine sample by intra- and interday assay were shown in "Table 7", "Figure 5" illustrate the chromatogram of analysis of baclofen in real human plasma.

Table 7. \% Recoveries after application of the proposed method for determination of baclofen in real human urine sample.

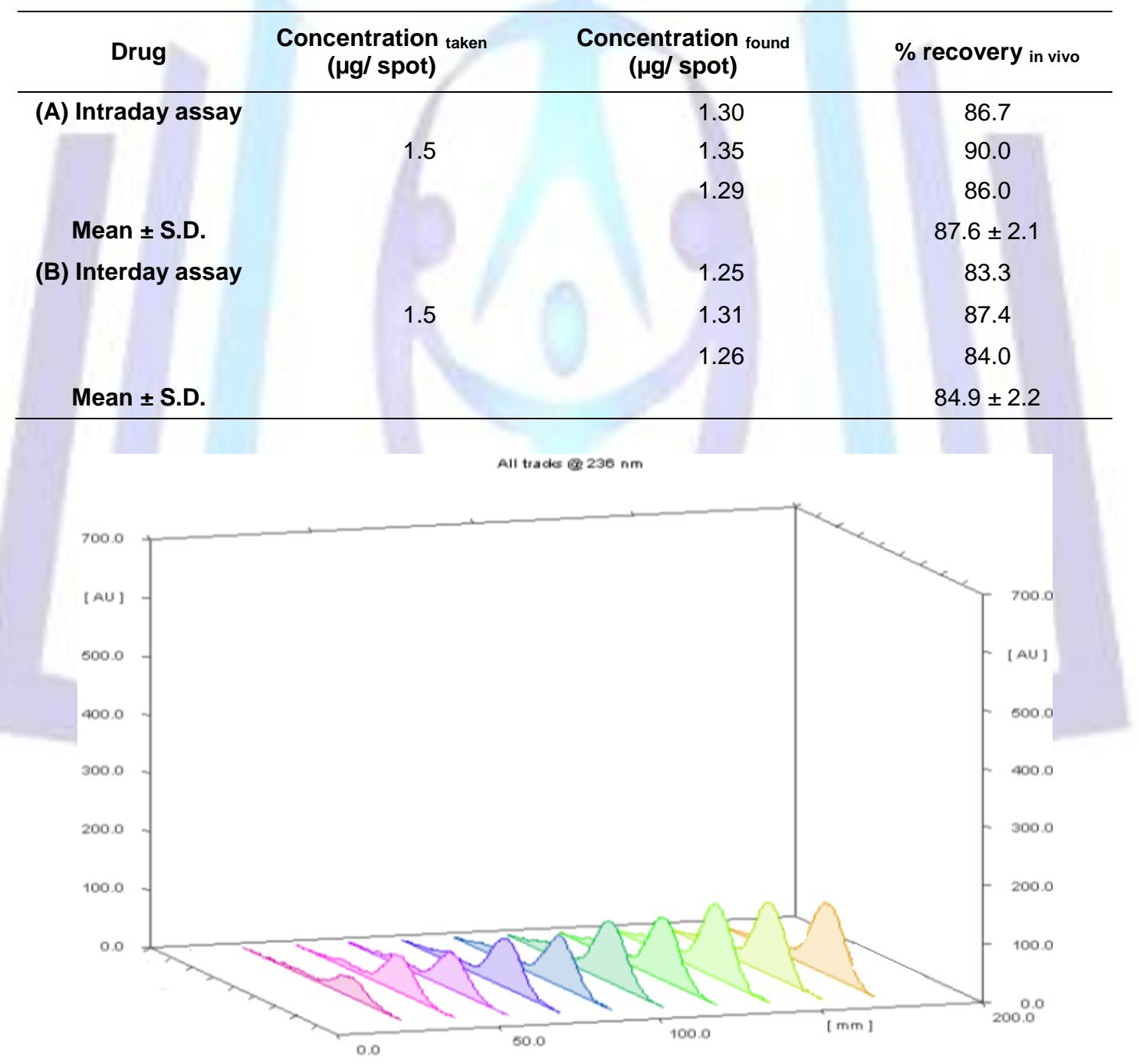

Fig 5: Chromatograms of baclofen in Real Human Urine.

\section{CONCLUSION}

In this work, HPTLC technique was developed and validated for determination of baclofen in bulk, pharmaceutical tablets and in real human urine and plasma. The proposed method is simple, accurate and highly selective for baclofen. It could be extended to study the stability of baclofen under different stress conditions. As the method separates the drug from its 
degradation product, it can be considered as a stability-indicating one. The satisfactory sensitivity and simplicity make the methods suitable for routine analysis of baclofen in quality control laboratories.

\section{REFERENCES}

[1] Aboul-Enein, H.Y.; Wainer, I.W. The Impact of Stereochemistry on Drug Development and Use, John Wiley \& Sons, New York, NY. 1997, 58.

[2] Stefan van Staden, R.I.; Rat'k, A.A. Enantioselective, potentiometric membrane electrodes based on cyclodextrins: application for the determination of R-baclofen in its pharmaceutical formulation, Talanta. 2006, 69, 1049-1053.

[3] Hosseinimehr, S.J.; Pourmorad, F.; Moshtaghi, E.; Amini, M. Colorimetric Determination of Baclofen with Ninhydrin Reagent and Compare with HPLC Method in Tablet, Asian J. Che. 2010, 22, 522-526.

[4] Saleh, H.M.; El-Henawee, M.M.; Ragab, G.H.; El-Hay, S.S. Utility of NBD-Cl for the spectrophotometric determination of some skeletal muscle relaxant and antihistaminic drugs, Spectrochim Acta. 2007, 67, 1284-1289.

[5] Rat'ko, A.A.; Stefan-van Staden, R.I. Determination of baclofen enantiomers in pharmaceutical formulations using maltodextrin-based enantioselective, potentiometric membrane electrodes, Farmaco. 2004, 59, 993-997.

[6] Bhushan, R.; Kumar, V. Indirect resolution of baclofen enantiomers from pharmaceutical dosage form by reversedphase liquid chromatography after derivatization with Marfey's reagent and its structural variants, Chromatographia. 2008, 22, 906-911.

[7] Siouffi, A.; Kaiser, G.; Leroux, F. J. Chromatogr. 1988, 450, 221-232.

[8] Kavran-Belin, G.; Rudaz, S.; Veuthey, J.L. Enantioseparation of baclofen with highly sulfated beta-cyclodextrin by capillary electrophoresis with laser-induced fluorescence detection, J. Sep. Sci..2005, 28, 2187-2192.

[9] Gu, Y.S.; Whang, C.W. Capillary electrophoresis of baclofen with argon-ion laser-induced fluorescence detection, J. Chromatogr. A. 2002, 972, 289-293.

[10] Miksa I.; Poppenga, R. Direct and rapid determination of baclofen (Lioresal) and carisoprodol (Soma) in bovine serum by liquid chromatography-mass spectrometry, J. Anal. Toxicol. 2003, 27, 275-283.

[11] Zhang, C.Y.; Yuan, M.; Huang, B.Y.; Ji, H.; Zhu, L. West Chin, J. Pharm. Sci. 2008, 23, 342-343.

[12] Tosunoglu, S.; Ersoy, L. Determination of baclofen in human plasma and urine by high-performance liquid chromatography with fluorescence detection, Analyst. 1995, 120, 373-375.

[13] Hefnawy, M.M.; Aboul-Enein H.Y. Enantioselective high-performance liquid chromatographic method for the determination of baclofen in human plasma, Talanta. 2003, 61, 667-673.

[14] Millerioux, L.; Brault, M.; Gualano, V.; Mignot, A. High-performance liquid chromatographic determination of baclofen in human plasma, J. Chromatogr. A. 1996, 729, 309-314.

[15] Chang, S.; Yang, H. Determination of Baclofen by Derivatization with Anthracene-2,3-dicarboxaldehyde Followed by Capillary Electrophoresis with Laser-induced Fluorescence Detection, Chromatographia. 2003, 57, 825-829.

[16] Chiang, M.T.; Chang, S.Y.; Whang, C.W. Analysis of baclofen by capillary electrophoresis with laser-induced fluorescence detection, J. Chromatogr. A. 2000, 877, 233-237.

[17] Li-Wei Cao; Hong Wang; Hua-Shan Zhang, Microchim. Acta. 2007, 158, 361-368.

[18] Li-Wei Cao; Hong Wang; Jin-Shu Li; Hua-Shan Zhang. 6-Oxy-(N-succinimidyl acetate)-9-(2'methoxycarbonyl)fluorescein as a new fluorescent labeling reagent for aliphatic amines in environmental and food samples using high-performance liquid chromatography, J. Chromatogr. A. 2005, 1063, 143-151.

[19] M. V. Mahadik, and S. R. Dhaneshwar. Application of stability-indicating HPTLC method for the quantitative determination of ezetimibe in pharmaceutical dosage forms, Asian J. Pharm. Sci.2 182-190 (2007).

[20] S. Motwani, R. Khar, F. Ahmad, S. Chopra, K. Kohli, and S. Talegaonkar. Application of a validated stability-indicating densitometric-TLC method to stress degradation studies on moxifloxacin, Anal. Chim. Acta582: 75-82 (2007).

[21] ICH, Q2B Validation of Analytical Procedure: Methodology, International Conference on Harmonization, Geneva, March 1996.

[22] The United States pharmacopeia 29 and NF 25 The National Formulary, American pharmaceutical Assiciation, Washington, DC, (2007).

[23] Manzoor, A.; Rajesh, M.; Sathish, K.S. A.; Maanasa, R..B.N. Zero order and First order Derivative Spectrophotometric Methods for determination of Baclofen in Pharmaceutical formulation, International Journal of ChemTech Research. 2011, 3, 933-937.

[24] Seyed, M.F.; Alireza, S.; Afshin, Z.; Khoddam, A. Bioequivalence studies of Baclofen tablets in healthy volunteers, Ind. J. Pharma. Res. 2003, 153-155

[25] Mahmoud, A. O.; Osama, H. A.; Sayed, M. D.; Tadayuki, U.; Tamer, Z. A. Spectrofluorimetric determination of certain antidepressant drugs in human plasma, Journal of Analytical Science and Technology. 2013, 4:5. 